\title{
Microemulsions based on propylene glycol diesters of caprylic and capric acids
}

\author{
Małgorzata A. Jaworska*, Elżbieta S. Sikora, Jan Ogonowski \\ Faculty of Chemical Engineering and Technology, Institute of Organic Chemistry and Technology, Cracow University \\ of Technology, Warszawska St. 24, 31-155 Krakow, Poland \\ "Corresponding author: mjaworska@chemia.pk.edu.pl
}

\begin{abstract}
The aim of this work was preparation and characterization of o/w nano and microemulsions containing Crodamol $\mathrm{PC}^{\circledR}$ as the oil phase. An influence of surfactants system applied in formulations on the properties of the obtained emulsions has been studied. The emulsions were prepared by phase inversion composition method. The measurement of the internal phase droplet size and the study of rheological properties were done. The obtained results showed that the prepared transparent emulsion systems are nano and microemulsion formulation. Moreover, it was concluded that the microemulsions stability and the size of the internal phase droplets depended on the type and the concentration of emulsifier and on the ratio of water phase to oil. Rheological studies have confirmed that the obtained microemulsions showed pseudoplastic behaviour.
\end{abstract}

Keywords: Propylene Glycol Dicaprylate/Dicaprate (Crodamol PC), nanoemulsions, microemulsions, low energy method.

\section{INTRODUCTION}

Emulsions are the most popular form of active substances vehicles used in cosmetic and pharmaceutical formulations. The novel class of emulsions with a high degree of fragmentation of the droplets of dispersed phase (about 20-200 nm) are nanoemulsions. Particles of nanoemulsions are too small to show intense light scattering, which makes them optically transparent or translucent. In contrast to microemulsions, nanoemulsions are characterized by kinetic stability only ${ }^{1-6}$. As a form of cosmetics, both types of emulsion with high degree of internal phase dispersion can relatively easily penetrate into the skin, exhibit a high degree of hydration and soften the skin and have a very good user properties (ease of spreading on the skin, no greasy feeling). Moreover an additional advantage of these emulsion types as a cosmetic forms is no inherent creaming, sedimentation, flocculation or coalescence observed within macroemulsions.

Most authors in their research used as an oil phase the low polarity oils such as decane ${ }^{7}$, hexadecane ${ }^{5}$, izohexadecane ${ }^{5,8,9}$, or paraffin oil ${ }^{10}$. Isopropyl myristate ${ }^{3,11,12}$ and triglycerides of caprylic/capric acid ${ }^{4,6}$ are often used as the oily phase with higher polarity. Also propylene glycol monocaprylic esters were applied by Sheikh Shafiq-un-Nabi and co-authors ${ }^{13}$ to obtaining nano and microemulsions. Selection of an appropriate oily phase is very important because it influences the selection of other ingredients.

Among the surfactants used to stabilize cosmetic nanoemulsions nonionic emulsifiers are preferred. Especially sorbitan fatty esters ${ }^{7}$, polyoxyethylene sorbitan esters ${ }^{7,13,14}$, ethoxylated alcohols and fatty acids ${ }^{\mathbf{5}, \mathbf{1 0}}$ and ethoxylated rapeseed oil derivatives ${ }^{3,4,11,13}$ are popular.

The most commonly used methods for nano and microemulsions preparation are $\mathrm{ar}^{2,3,6,15,16}$ :

- high-energy emulsification methods:

- high-pressure homogenization,

- microfluidization.

- low energy emulsification:

- phase inversion temperature,
- phase inversion composition,

- spontaneous emulsification.

The high energy emulsification methods use the mechanical energy, originating mainly from the mechanical devices such as high speed mixer, high-pressure homogenizer and ultrasonic generator. While the low-energy methods are based on the chemical energy stored in the ingredients of the emulsion (mainly surfactants) ${ }^{17}$. Emulsifiers decrease interfacial tension and thus reduce the energy input required to obtain emulsions with small and uniform droplet size ${ }^{4,5}$.

The aim of this work was to prepare and characterize of o/w nano and microemulsions containing Propylene Glycol Dicaprylate/Dicaprate as the oil phase. Crodamol $\mathrm{PC}$ is the popular cosmetics ingredient, using in skin care products as an emollient, which is characterized by good user properties, e.g. easy spreading, no occlusive. The phase diagrams of the ternary system: Crodamol PC/ surfactant/water were determined to specify the area of nanoemulsions occurrence and to select an appropriate emulsion composition ${ }^{15}$. The effect of the concentration and the type of emulsifier on the properties of the emulsions were tested.

\section{MATERIALS AND METHODS}

In the studies, non-ionic emulsifiers with different HLB and different chemical nature (i.e. ethoxylated castor oil, ethoxylated fatty acid esters of sorbitol and ethoxylated fatty acid esters of glycerol) have been applied to the obtained stable emulsion (Table 1). They were kindly supplied by Croda and Degussa. The surfactants selection was made because of their good performance and lack of irritation and toxicity to the skin. Crodamol PC ${ }^{\circledR}$ (INCI: Propylene Glycol Dicaprylate/Dicaprate), which was also kindly supplied by Croda, was used as an oil phase. The aqueous phase was distilled water. 
Table 1. Emulsifiers used in the studies

\begin{tabular}{|l|c|c|c|}
\hline Emulsifier & INCI & $\begin{array}{c}\text { Producer/ } \\
\text { Distributor }\end{array}$ & HLB \\
\hline Etocas 40 & PEG-40 Castor Oil & Croda & 13.0 \\
\hline Tego SMO 80 V & Polysorbate 80 & Degussa & 15.0 \\
\hline Tagat L2 $^{\circledR}$ & $\begin{array}{c}\text { PEG-20 Glyceryl } \\
\text { Laurate }\end{array}$ & Degussa & 16.0 \\
\hline
\end{tabular}

\section{Formation of $\mathrm{o} / \mathrm{w}$ nano and microemulsions}

Emulsions were prepared by stepwise water (W) addition to the mixture of oil and surfactant $(\mathrm{O} / \mathrm{S})$, at room temperature $\left(25^{\circ} \mathrm{C}\right)$. The mixture was stirred using a mechanical stirrer, IKA RW20 equipped with speed control. The emulsification process parameters are shown in Table 2. The effect of the concentration and the type of emulsifier on properties of the emulsions were tested.

Table 2. Emulsification process parameters

\begin{tabular}{|l|c|}
\hline Parameter & Value \\
\hline Emulsification time & $20 \mathrm{~min}$. \\
\hline Emulsification temperature & $25^{\circ} \mathrm{C}$ \\
\hline Stirrer speed & $150-1500 \mathrm{rpm} / \mathrm{min}$ \\
\hline Method of phase connection & drop by drop \\
\hline $\begin{array}{l}\text { Phase inversion composition } \\
(\mathrm{PIC})\end{array}$ & $\mathrm{W} \rightarrow \mathrm{O} / \mathrm{S}$ \\
\hline
\end{tabular}

\section{Construction of phase diagram}

Pseudoternary phase diagram were developed using the aqueous titration method. Slow titration with the aqueous phase was performed for each combination of oil and surfactant mixture. The amount of the added aqueous phase was varied to produce water concentration in the range of $5 \%$ to $30 \%$. For each phase diagram at a specific surfactant ratio, the ratios of oil to the mixture of surfactant, were varied as 0.4:0.6, 0.375:0.625, 0.28:0.72 (Fig. 2), 0.375:0.625, 0.29:0.71 (Fig. 3) and 0.64:0.36, 0.29:0.71 (Fig. 4). The mixtures of oil and surfactant were diluted with water drop wise, under moderate mechanical stirring.

\section{Assessment of physicochemical properties}

The physical properties of the obtained formulations were evaluated in the next stage of the research. The emulsions stability were investigated by changing the temperature test. The $\mathrm{pH}$ values of the emulsions were determined using digital $\mathrm{pH}$ meter (Metler Toledo HI 221). The emulsion type was checked by dilution test, using the fact that emulsions can be diluted only with a liquid which is mixed well with the continuous phase, $\mathrm{o} / \mathrm{w}$ emulsions are water soluble, without the formation of aggregates. On the other hand, emulsions of w/o type are not diluted in water ${ }^{\mathbf{1 8}}$. The rheological properties of the emulsions were studied using Brookfield Rheometr Model-R/S-plus, equipped with a measuring system cone-plate type, cone C75-1.

\section{MEASURMENT OF DROPLET SIZE}

The average internal phase droplet size of the obtained emulsions were measured by Beckman Coulter N4 Plus Particle Size Analizer using Photon Correlation Spectroscopy (PCS), which determines particle size by measuring the rate of fluctuations in laser light intensity scattered by particles as they diffuse through a fluid.

\section{RESULTS AND DISSCUSION}

\section{Pseudo-ternary phase diagram}

As mentioned previously all formulations were received by low energy emulsification method, by dropwise addition of water to the mixture of oil/surfactant. The phase diagrams of ternary system: Crodamol PC/surfactant/water were done to specify the area of nano and microemulsions occurrence (Figs. 1-3).

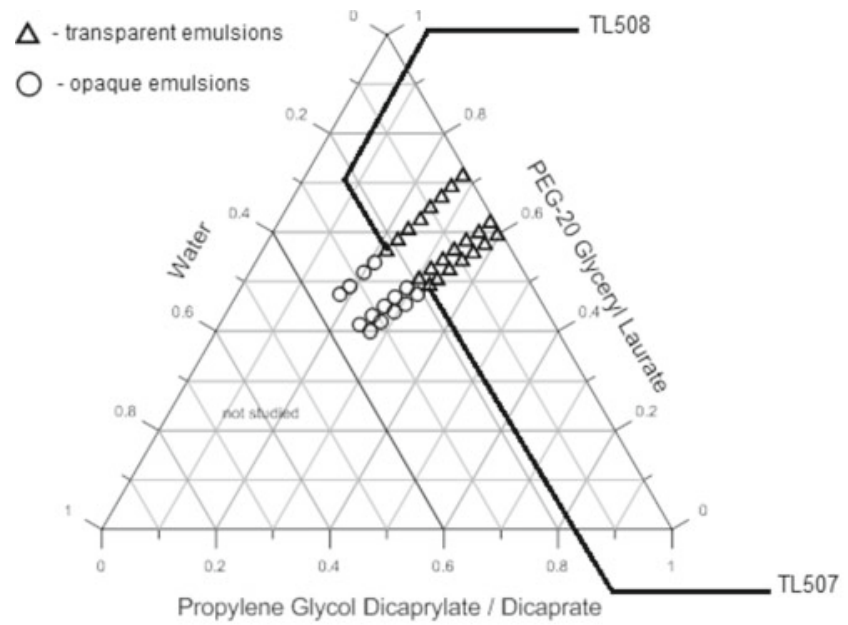

Figure 1. The pseudo-ternary phase diagram of water/PEG20 Glyceryl Laurate/Propylene Glycol Dicaprylate/ Dicaprate system at $25^{\circ} \mathrm{C}$

The pseudoternary phase diagram with various weight ratios of Tagat L2 (PEG-20 Glyceryl Laurate) to Crodamol PC (Propylene Glycol Dicaprylate/Dicaprate) are presented in Fig. 1. The ratios of oil to the surfactant were varied as 0.4:0.6, 0.375:0.625 and 0.28:0.72. The transparent, nanoemulsion region is presented in phase diagram. Emulsions with the maximum content of the aqueous phase (TL507, TL508) were chosen later for the analysis.

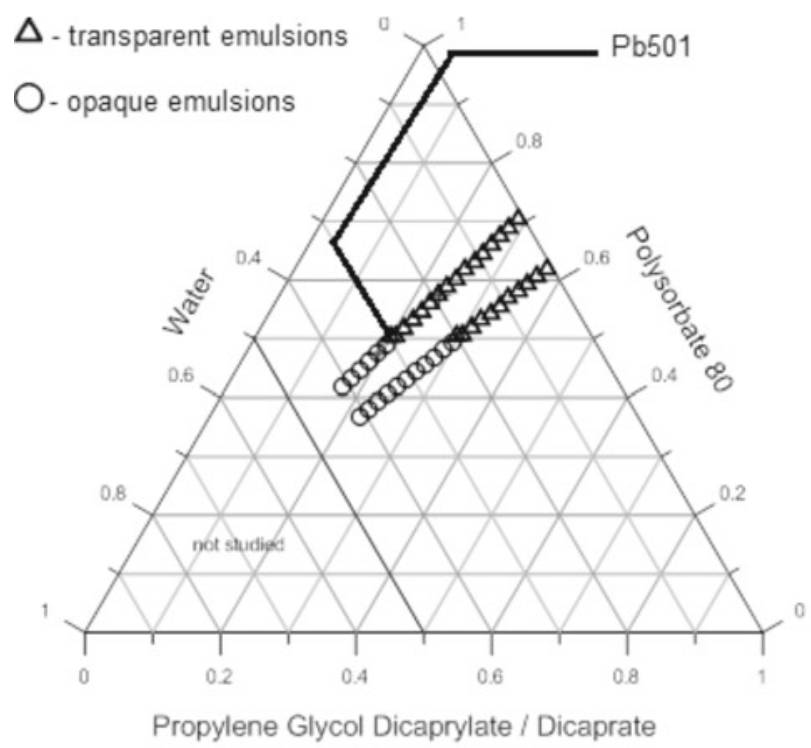

Figure 2. The pseudo-ternary phase diagram of water/Polysorbate 80/Propylene Glycol Dicaprylate/Dicaprate system at $25^{\circ} \mathrm{C}$

Figure 2 shows the pseudoternary phase diagram with various weight ratios of Tego SMO $80 \mathrm{~V}$ (Polysorbate 80) to Crodamol PC (Propylene Glycol Dicaprylate/Di- 
caprate). The ratios of oil to the emulsifier were varied as $0.375: 0.625$ and $0.29: 0.71$. The emulsion with the maximum content of the aqueous phase ( $\mathrm{Pb501}$ ) was chosen for the analysis.

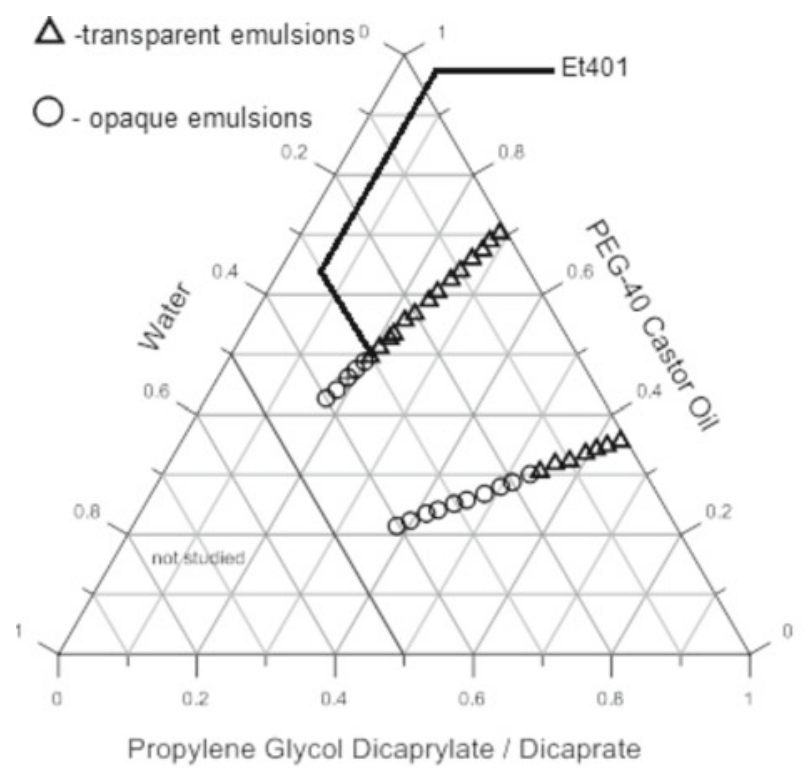

Figure 3. The pseudo-ternary phase diagram of water/PEG-40 Castor Oil/Propylene Glycol Dicaprylate/Dicaprate system at $25^{\circ} \mathrm{C}$

The pseudoternary phase diagram with various weight ratios of Etocas 40 (PEG-40 Castor Oil) to Crodamol PC (Propylene Glycol Dicaprylate/Dicaprate) is presented in Fig. 3. The ratios of oil to Etocas 40 was varied as 0.64:0.36 and 0.29:0.71. The transparent emulsion region is presented in phase diagram. The emulsion with the maximum content of the aqueous phase (Et401) was chosen for the analysis.

The rest of the studied region on the phase diagrams represents turbid, opaque emulsions based on visual observation. It should be noticed that with increasing the water content, the emulsions became opaque systems.

On the basis of the results obtained an appropriate emulsions composition was selected (Table 3).

\section{Characterization of selected emulsions}

In Table 4 and in Figs. 4-6 the physicochemical properties of the obtained stable systems are shown.

The data presented in Table 4 shows that by using the PEG-20 Glyceryl Laurate, Polysorbate 80, PEG-40 Castor Oil we could obtain stable transparent systems containing as an oil phase Crodamol PC. Thus, a common feature of the discussed preparations is the need to use ethoxylated emulsifiers. It should also be noticed that the TL507 emulsion, which has the same qualitative composition as the TL508 emulsion, but the higher amount of oil at the reduced content of water and surfactant (Table 3), is characterized by a bigger size of the dispersed phase droplets (Table 4). It can also be deduced that the ratio of oil phase to the aqueous phase also affects the properties of the prepared emulsions. Notable is the fact that the emulsions can be obtained in the ambient temperature, the method does not require energy input.

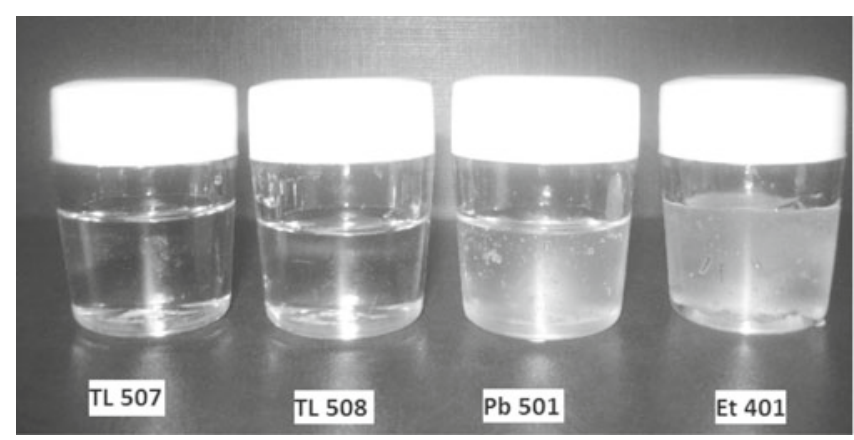

Figure 4. Optical appearance of compositions TL507, TL508, Pb501, Et401

\section{Stability of emulsions}

The samples were stored, at ambient temperature, for 24 hours, 47 hours, one week and one month. During the time the stability of the formulations were assessed visually. The emulsions were transparent and stable. The phase separation and degradation were not observed durnig these 2 months. All emulsion systems were also stable at $36.5^{\circ} \mathrm{C}(309.5 \mathrm{~K})$. All formulations showed no change in clarity and phase behavior.

Table 3. Formulations of the emulsions

\begin{tabular}{|c|c|c|c|c|c|}
\hline \multirow[b]{2}{*}{ Phase } & \multirow[b]{2}{*}{ Ingredients } & \multicolumn{4}{|c|}{ Percent composition [\%] } \\
\hline & & TL507 & TL508 & Pb501 & Et401 \\
\hline W & Water & 17 & 22 & 30 & 30 \\
\hline 0 & Crodamol PC & 33 & 22 & 20 & 20 \\
\hline \multirow{3}{*}{$S$} & Tagat L2 & 50 & 56 & - & - \\
\hline & Tego SMO 80V & - & - & 50 & - \\
\hline & Etocas 40 & - & - & - & 50 \\
\hline $\mathrm{O} / \mathrm{S}$ & & $0.4: 0.6$ & $0.28: 0.72$ & $0.29: 0.71$ & 0.29:0.71 \\
\hline
\end{tabular}

TL507- emulsion stabilized by $50 \%$ of Tagat L2,

TL 508 - emulsion stabilized by $56 \%$ of Tagat L2,

Pb501 - emulsion stabilized by Tego SMO $80 \mathrm{~V}$,

ET401 - emulsion stabilized by Etocas 40.

Table 4. Properties of the stable systems

\begin{tabular}{|l|c|c|c|c|c|}
\hline Formulations & Type of emulsion & $\mathrm{pH}$ & Stability & Appearance & Average droplet size [nm] \\
\hline TL507 & O/W & 5.56 & Stable & transparent & 179 \\
\hline TL508 & O/W & 5.57 & Stable & transparent & 110 \\
\hline Pb501 & O/W & 5.43 & Stable & transparent & 209 \\
\hline Et401 & O/W & 5.45 & Stable & transparent & 700 \\
\hline
\end{tabular}




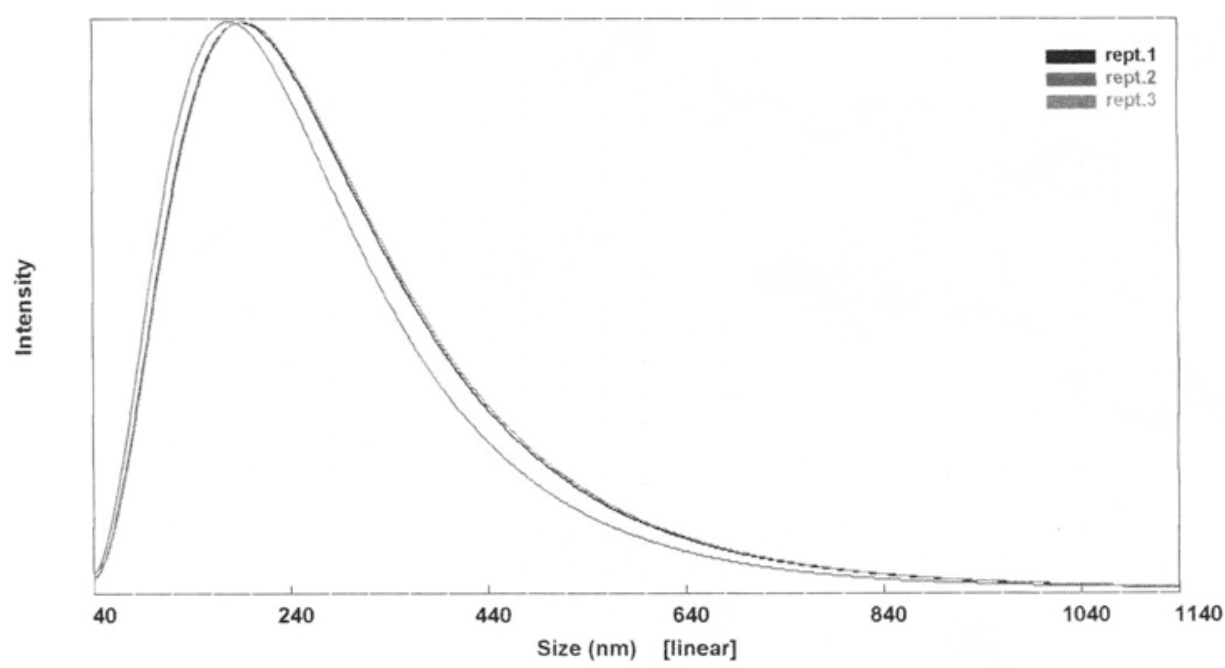

Figure 5. The average droplet size of microemulsion Pb501

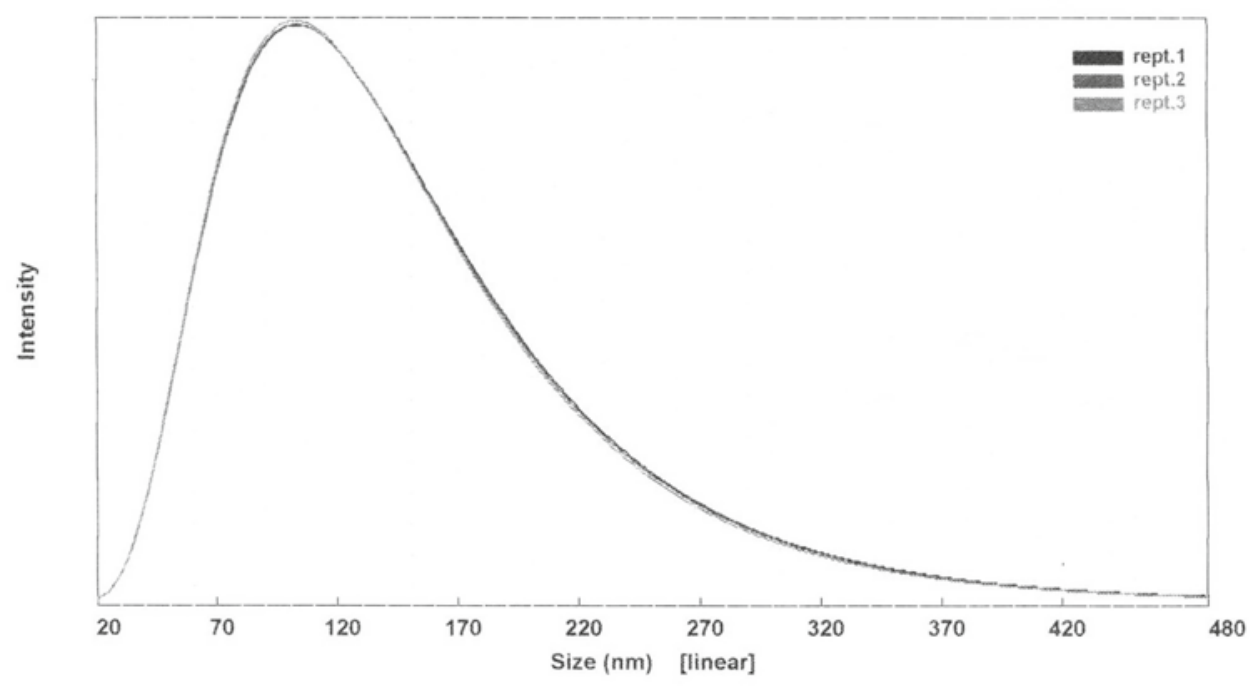

Figure 6. The average droplet size of nanoemulsion TL508

\section{Rheological characterization}

Figures 7-8 show the viscosity curves of the studied emulsifiers (Fig.7) and the obtained emulsions (Figs. 8-9)

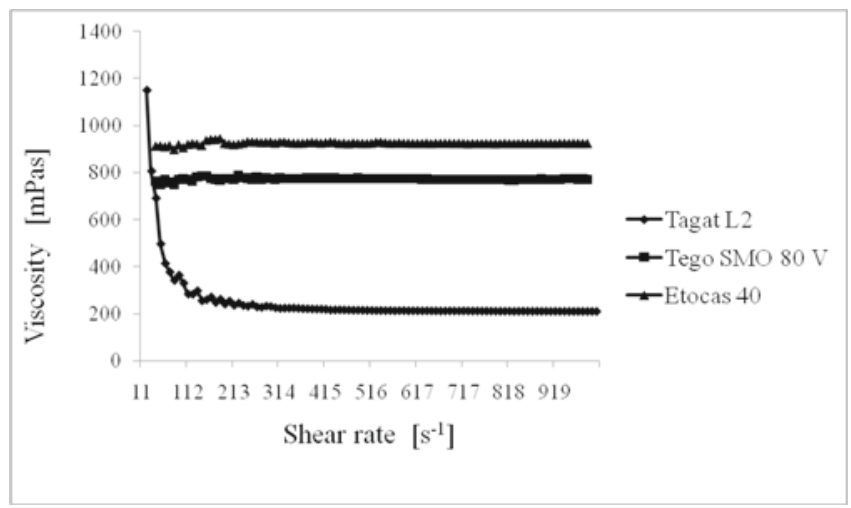

Figure 7. Comparison of emulsifiers viscosity applied in the obtained emulsions

The data presented in Fig. 7 show that the Tagata L2 (PEG-20 Glyceryl Laurate) emulsifier exhibited pseudoplastic rheological behavior. Whereas the Tego SMO $80 \mathrm{~V}$ (Polysorbate 80) and Etocas 40 (PEG-40 Castor Oil) emulsifiers are the Newtonian liquids. It is noteworthy that these emulsifiers are characterized by much higher viscosity than ethoxylated glyceryl laurate.

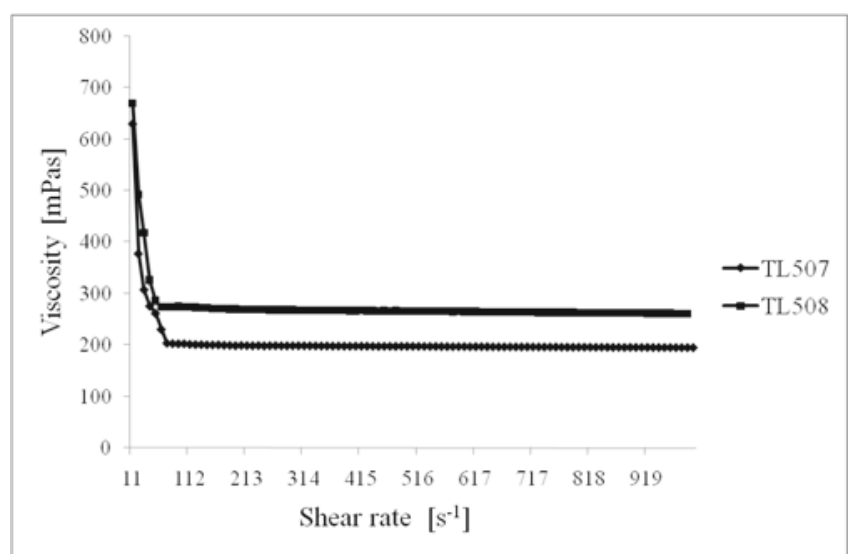

Figure 8. Effect of emulsifier type on the viscosity of the obtained emulsions, at $25^{\circ} \mathrm{C}$

Figure 8 shows that both the TL507 and TL508 emulsions are characterized by pseudoplastic behaviour. It is worth noting that the TL508 emulsion is characterized by higher viscosity than the TL507 emulsion, it is probably due to the larger emulsifier (Tagata L2) content $(6 \%)$, (Table 3). 


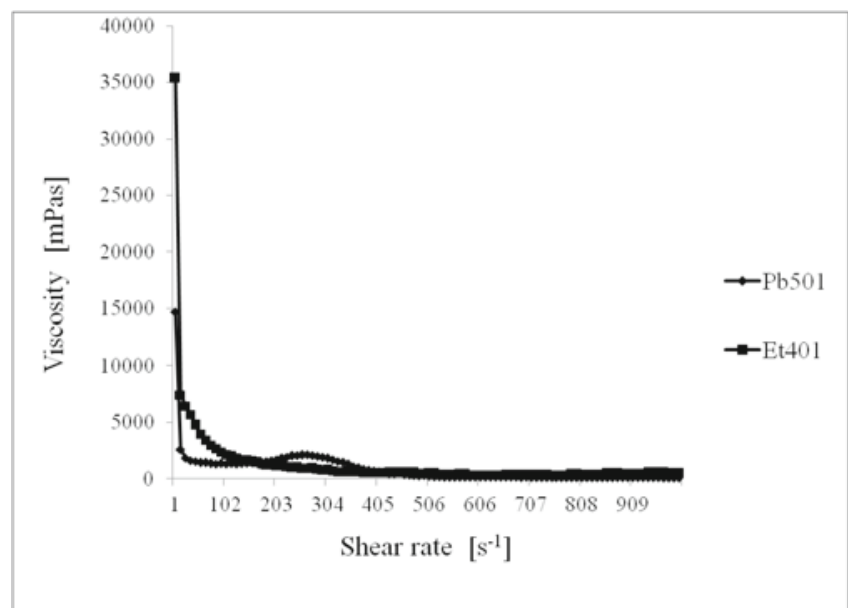

Figure 9. Influence of emulsifier type on the viscosity of the obtained emulsions at $25^{\circ} \mathrm{C}$

Emulsions Pb501 and Et401 are the non-Newtonian liquids also with pseudoplastic rheological behaviour. Moreover the Et402 emulsion is characterized by higher viscosity than Pb501. The observed phenomena are related to differences in viscosity surfactants. Etocas 40 (PEG-40 Castor Oil) is greasy substance while ethoxylated sorbitan oleate (Tego SMO $80 \mathrm{~V}$ ) is a clear viscous liquid. Etocas 40 can also be used as a consistency regulator. It should also be noticed that both emulsions are much more viscous than the TL507 and TL508 emulsions (Fig. 8). Perhaps this is due to the difference in viscosity emulsifiers which they are composed (Fig. 7).

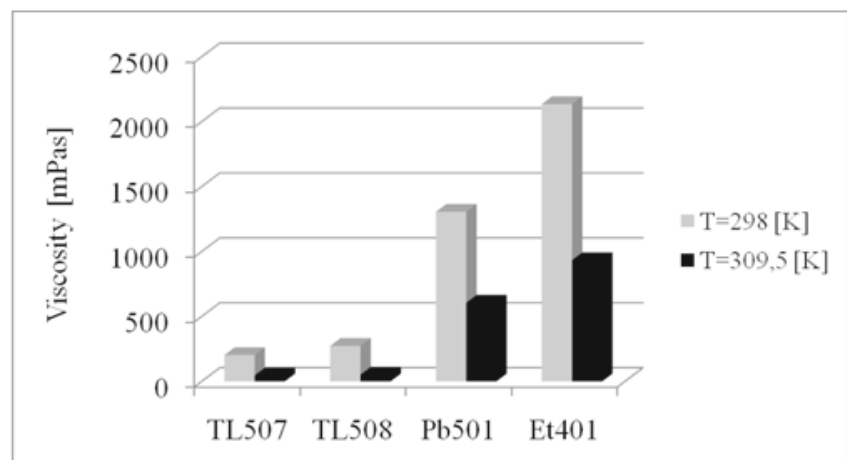

Figure 10. The dependence of the emulsion viscosity on temperature, at shear rate $\gamma=1001 / \mathrm{s}$

The measurements of the emulsion viscosity were carried out for the selected shear rate $(\gamma=1001 / \mathrm{s})$, for two temperatures: at $25^{\circ} \mathrm{C}(298 \mathrm{~K})$ and at $36.5^{\circ} \mathrm{C}$ $(309.5 \mathrm{~K})$ which is close to the human body temperature. The data presented in figure 10 show that the viscosity of all emulsion formulations decreased with the increase of temperature. That means that after an application of the emulsions, during the contact with the skin, they would be easy to spread.

\section{CONCLUSION}

The following conclusions were found on the basis of studies:

1. Caprylic and Capric diesters of propylene glycol can be used as an oil phase in nano and microemulsion formulation using the phase inversion method (PIC).
2. To obtained stable and transparent systems the nonionic ethoxylated, hydrophilic emulsifiers could be applied.

3. The type, concentration and viscosity of the used emulsifier and the ratio of water to oil phase affected the properties of the obtained emulsions.

4. It was found that the average droplet sizes increase significantly with the increase of oil contents in the formulation, and with the decrease of surfactant concentartion.

5. The obtained emulsions are the non-Newtonian liquids with a pseudoplastic rheological behaviour.

\section{LITERATURE CITED}

1. Somasundaran, P.,. Chakraborty, S, Deo, N. \& Somasundran, T. (2006). Nanoencapsulation for Extraction and Release of Fragrance. Cosmetics\&Toiletries. 12, 47-54.

2. Kothekar, S.C., Waghmare, J.T. \& Momin, S.A. (2006). Rationalizing and Producing Nanoemulsions for Personal Care. Cosmetics\&Toiletries. 7, 51-56.

3. Usón, N., Garcia, M.J. \& Solans, C. (2004). Formation of water-in-oil $(\mathrm{W} / \mathrm{O})$ nano-emulsions in a water/mixed non-ionic surfactant/oil systems prepared by a low-energy emulsification method. Colloids and Surfaces A: Physicochem. Eng. Aspects. 250, 415-421. DOI: 10.1016/j.colsurfa.2004.03.039.

4. Sadurni, N., Solans, C., Azemar, N. \& Garcia-Celma, M.J. (2005). Studies on the formation of O/W nano-emulsions, by low energy emulsification methods, suitable for pharmaceutical applications. European Journal of Pharmaceutical Sciences. 26, 438-445. DOI: 10.1016/j.ejps.2005.08.001.

5. Tadros, T., Izquierdo, P., Esquena, J. \& Solans, C. (2004). Formation and stability of nano-emulsions. Advances in Colloid and Interface Science. 108-109, 303-318. DOI: 10.1016/j. cis.2003.10.023.

6. Bouchemal, K., Briancon, S., Perrier, E. \& Fessi, H. (2004). Nano - emulsion formulation using spontaneous emulsification: solvent, oil and surfactant optimisation. International Journal of Pharmaceutics. 280, 241-251. DOI: 10.1016/j.1016/j. ijpharm.2004.05.016.

7. Porras, M., Solans, C., Gonzalez, C. \& Gutierrez, J.M. (2008). Properties of water-in-oil (W/O) nano-emulsions prepared by a low-energy emulsification method. Colloids and Surfaces A: Physicochem. Eng. Aspects. 324, 181-188. DOI: 10.1016/j.colsurfa.2008.04.012.

8. Izquierdo, P., Feng, J., Esquena, J., Tadros, T.F., Dederen, J.C., Garcia, M.J., Azemar, N. \& Solans, C. (2005). The influence of surfactant mixing ratio on nano-emulsion formation by the pit method. Journal of Colloid and Interface Science. 285, 388-394. DOI: 10.1016/j.jcis.2004.10.047.

9. Peng, L-C., Liu, C-H., Kwan, C-C. \& Huang, K-F. (2010). Optimization of water-in-oil nanoemulsions by mixed surfactants. Colloids and Surfaces A: Physicochem. Eng. Aspects. 370, 136-142. DOI: 10.1016/j.colsurfa.2010.08.060.

10. Fernandez, P., Andre, V., Rieger, J. \& Kühnle, A. (2004). Nano-emulsion formation by emulsion phase inversion. Colloids and Surfaces. 251, 53-58. DOI: 10.1016/j.colsurfa.2004.09.029.

11. Yang, H.J., Cho, W.G. \& Park, S.N. (2009). Stability of oil-in-water nano-emulsions prepared using the phase inversion composition method. Journal of Industrial and Engineering Chemistry. 15, 331-335. DOI: 10.1016/j.jiec.2009.01.001.

12. Patel, M.R., Patel, R.B., Parikh, J.R., Bhatt, K.K. \& Solanki, A.B. (2010). Investigating the effect of vehicle on in vitro skin permeation of ketoconazole applied in $\mathrm{O} / \mathrm{W}$ microemulsions. Acta Pharmaceutica Sciencia. 52, 65-77.

13. Shafiq-un-Nabi, S., Shakeel, F., Talegaonkar, S., Ali, J., Baboota, S., Ahuja, A., Khar, R.K. \& Ali, M. (2007). Formulation Development and Optimization Using Nanoemulsion Technique: A Technical Note. AAPS Pharm. Sci. Tech. 8, E1-E6. 
14. Caldero, G., Garcia-Celma, M.J. \& Solans, C. (2011). Formation of polymeric nano-emulsions by a low-energy method and their use for nanoparticle preparation. Journal of Colloid and Interface Science. 353, 406-411. DOI: 10.1016/j. jcis.2010.09.073.

15. Kotyla, T., Kuo, F., Moolchandani, V., Wilson, T. \& Nicolosi, R. (2008). Increased bioavailability of a transdermal application of a nano-sized emulsion preparation. International Journal of Pharmaceutics. 347, 144-148. DOI: 10.1016/j. ijpharm.2007.06.045.

16. Chen, H.,. Chang, X, Weng, T., Zhao, X., Gao, Z., Yang, Y., Xu, H. \& Yang, X. (2004). A study of microemulsion systems for transdermal delivery of triptolide. Journal of Controlled Release. 98, 427-436. DOI: 10.1016/j.jconrel.2004.06.001.

17. Sole, I., Pey, C.M., Maestro, A., Gonzalez, C., Porras, M., Solans, C., Gutierrez, J.M. (2010). Nano-emulsions prepared by the phase inversion composition method: Preparation variables and scale. Journal of Colloid and Interface Science. 344, 417-423. DOI: 10.1016/j.jcis.2009.11.046.

18. Zieliński, R. (2000). Surfaktanty, towaroznawcze i ekologiczne aspekty ich stosowania, Wydawnictwo Akademii Ekonomicznej w Poznaniu. [in Polish]. 